\title{
versants
}

\section{Las minúsculas de Itzíar López Guil. En torno a Asia}

\author{
Pedro Ruiz Pérez \\ Universidad de Córdoba
}

\begin{abstract}
En clave estética, la opción de Itzíar López Guil por la minúscula materializa una opción en las fronteras entre prosa y poesía, entre el lenguaje cotidiano y las formas de extrañamiento. Como con los signos de puntuación, el rechazo a la mayúscula supone colocarse al margen de lo establecido, de la autoridad, de la Academia, y situar la emoción fuera del escaparate de la exclamación o del tono exaltado, mayúsculo. En el legado de la poesía de la experiencia y la otra sentimentalidad, con Asia se abre una reflexión sobre sus límites y alcance, que nunca son los mismos lejos del carácter epigonal.
\end{abstract}

Keywords: Itzíar López Guil, Asia, lenguaje poético, experiencia, composición

El «escritor postmoderno ejemplar», como ha sido señalado a propósito de Ricardo Piglia, «es un profesor que además publica novelas» ${ }^{\perp}$. En ese caso, Itzíar López Guil sería una escritora moderna o, si se prefiere, un ejemplo de administración a contracorriente de las relaciones de una similar doble faz ante las letras. Profesora en la Universidad suiza, contempla también la literatura hispánica con algo de extrañamiento y como una forma de puente con la realidad que quedó a unos miles de kilómetros y un par de décadas. Nacida con la antología de los novísimos, su tiempo de lecturas viene a coincidir con la eclosión de «la otra sentimentalidad» y el asentamiento como tendencia dominante de la poesía de la experiencia, en cuya generación se inserta, dentro de la cohorte más joven. Incorporada a la experiencia transicional en un momento más tardío que los referentes de esta poesía (su primer libro se publica en el año 2000), los matices del diálogo entre la profesora y la poeta se hacen distintivos y le dan a su voz un timbre peculiar. Sin perder un cierto aire de familia y sin caer en los pruritos de la singularidad, otros aires circulan entre sus versos, y no siempre, al menos de manera manifiesta, como resultado de otras lecturas, más bien por una manera propia de indagar en la intimidad y en sus relaciones con el tiempo y aun con la historia.

Entre la premisa conceptual y la hipótesis de lectura de los versos de Asia, el libro en el que se centrarán estas notas ${ }^{2}$, hemos de partir de una ob-

I Daniel Link, en Página/ı2, citado en la contraportada de Ricardo Piglia, Nombre falso, Barcelona, Debolsillo, 2014.

2 Madrid, Biblioteca Nueva, 2011. 
servación: lejos de la a veces obscena ostentación de lo «metaliterario», una arraigada y elaborada conciencia del hecho poético, estético y ficcional no siempre tiene que traducirse en una manifestación explícita, en un juego de referencias donde en demasiadas ocasiones se borran las fronteras entre la reflexión y el reflejo. Así ocurre cuando la barroca metáfora sobre la condición de las apariencias deriva en narcisismo u onanismo; y tanto da que la impotencia que revela se deba a inconsistencia adolescente o a disolución senil, casi siempre con la melancolía como fondo. Frente a las estrategias que recurren a los ecos por un escepticismo ante las palabras, hay otras vías en que el poema se apoya en un denso andamiaje literario para alzar su vuelo, pero, como en la obra civil, retira los restos del proceso de construcción, por más que estos resulten apreciables al ojo avisado en las huellas de la reflexión, en los discretos usos de los códigos, siempre en los intersticios del verso y en su propia materia, no en la referencia más o menos simplificada.

Si comenzamos justamente por la referencia en la recomposición de los itinerarios de lectura que propone este libro, podemos arrancar de una interrogación: ¿Por qué «Asia» en la portada, en la puerta de acceso de un poemario que no habla de Asia? Es más, estamos ante un libro mucho más alejado del exotismo que de una revisión de un mundo cercano, incluso con rasgos costumbristas, como los de «Unas sidrinas, una tabla de quesos», el único epígrafe o título que encabeza un poema de los de la primera parte del poemario; solo que hoy sabemos que el costumbrismo no es una cuestión de objetos o realidades objetivas, sino de miradas, y una evocación de la de Claudio Rodríguez hacia los tendederos de ropa en Don de la ebriedad puede bastar para zanjar un posible debate. Dejemos, pues, las consideraciones pretextuales y adentrémonos en la experiencia de la tabla de quesos, con la pregunta de fondo, ¿de qué hablamos cuando hablamos de Asia, en este caso sí, con mayúscula?

El poemario se articula en dos partes de extensión muy distinta, «Las olas», con 23 poemas, $y$ «Asia», con 5 . Entre ambas se mantienen unos juegos de simetrías nada ocultos, tensando las relaciones entre los elementos de cada parte y, a la vez, el diálogo entre ambas, donde la disminución de la materia y la identidad del nombre con el del libro establece una línea de lectura en progreso: de un apartado más profuso y marcado desde su epígrafe por el movimiento, hasta un ámbito en principio más delimitado, pero abierto en su simbología. El mar y la tierra, el viaje y la meta, el tiempo fugaz y el remansamiento.

Los poemas de «Olas» se disponen en dos grupos de II en torno a un poema central: II / I / II, con un primer trayecto que revive la infancia, el tiempo de una armonía quizá idealizada, donde el sujeto se identifica con un entorno de rasgos naturales, con el doble sentido de ese verbo complejo y plagado de trampas: la voz lírica accede a un conocimiento de sí, de su 
identidad personal, a través de un juego de identificación con el mundo que le rodea, mejor dicho, que le rodeaba, como queda reflejado por el uso de los verbos en pretérito y las menciones de la «memoria», que cierran los poemas I y II, es decir, el primero y el último del primer bloque de «Olas». Porque en la segunda parte en la contemplación de ese mundo se introduce la distancia, a partir de la conciencia de una mirada con algo de retrospectiva, pero siempre muy consciente de la actualidad de su momento. Si no instalada del todo en un sentimiento de la pérdida, sí late en la voz de estos poemas finales la conciencia de que el pasado solo puede recuperarse a través de este ejercicio en el que se halla, con una consideración de lo pretérito que ha de pasar por la experiencia de la escisión respecto a quien fue para poder restaurar el orden sobre la fluidez de las olas. En el centro, a modo de eje de simetría, la composición I2 actúa de clave de bóveda, sosteniendo y ajustando las fuerzas contrapuestas de las dos partes. Punto de inflexión, su inclusión marca el giro de una trayectoria, un retornar de una manera distinta (como las olas), un renacimiento. La numerología siempre es escurridiza, pero creo que en este caso es algo más que una casualidad o una mera sugerencia que el número del poema coincida con el del último mes del ciclo anual, el que señala un final y un comienzo, con una experiencia de renovación de cara al nuevo ciclo. Además de una pieza esencial en la arquitectura de la primera parte del poemario, este poema central es también una clave de lectura, a partir de su reflexión sobre la condición y los efectos del lenguaje, del papel instituyente de la expresión (poética, hemos de precisar), pero también de sus limitaciones. La indagación se articula en tres partes, como el conjunto al que sirve de eje, y, con su misma pauta, arranca de la asunción de lo inmediato, de lo dado, y desemboca en una conciencia del desgaste, de una pérdida que es el signo de la vida: «Parecen las palabras / blandas siluetas / que nos ponen en los labios al nacer ${ }^{3}$, son los versos iniciales, marcados por una blandura que es suavidad e inconsistencia, goce y apariencia, sensación y fugacidad, porque, como apunta la segunda estrofa en su arranque, «cada voz crece y muere con nosotros / artífices de cuerpos», derivando hacia la conciencia del artificio la inicial imagen de naturalidad, en una secuencia que lleva desde el nacimiento a la muerte, una muerte que también afecta al lenguaje porque, leemos en la conclusión de la tercera y última estrofa, «ese roce / está limando las entrañas / de mi vocabulario». Las palabras se han hecho propias y se han materializado en el vocabulario del sujeto lírico, para definir su identidad, solo que ese entrañamiento es también la causa de su desgaste, de las limitaciones en una expresión, que ahora puede intentarse al margen de la ingenuidad, con la conciencia del tiempo y de sus efectos.

3 López Guil, Asia, op. cit., p. 26. 
Las olas evocan movimiento, pero también repetición, continuidad, casi eternidad. «La mer, la mer / toujours recommencée», evocaba Valéry en el arranque de Le cimetière marin, y no es otra la imagen transmitida por el sucederse de las olas, siempre iguales y siempre distintas. En el texto la continuidad se apoya en la reiteración de una imaginería propia y en la recurrencia de elementos de enlace. Así sucede, a modo de ejemplo, entre el poema inicial y el que abre la tercera parte, el I3; la imagen del despertar recreada en el primero ( $«$ Se abren las pupilas a la luz / y empiezan a adherirse / como larvas / al espacio que acoge su existencia $\left.{ }^{4}\right)$ reaparece en el equivalente del bloque final («Despierta'. / Voz del mundo que llama / midiendo tus minutos de trabajo» $\left.{ }^{5}\right)$, y, en la continuidad, los cambios se hacen evidentes: la intervención extraña, la voz ajena, la escisión latente en el uso de la segunda persona y la referencia al trabajo y la materialización del tiempo a través de su cómputo y medida, nos anuncian que hemos atravesado una frontera, que estamos al otro lado del espejo. El mecanismo se reitera en las composiciones siguientes, la 2 y la I4, con su paralela evocación de la naturaleza y la experiencia de la misma, primero como armonía («El día en que toqué / por primera vez el mundo / los árboles estaban suaves, / lúcidos en su existir / sin nombre ni condena»; y nótese la identificación apuntada por los dos sustantivos finales) y más tarde como fractura y desorden («Entra la aurora y rompe el valle, / hace añicos el cielo, / aturde las cigüeñas en tus ojos, / echa a volar tu vientre entre las sábanas»); el mismo desplazamiento hacia la segunda persona acompaña el desdoblamiento del momento inaugural, como este pasa de la experiencia irrepetible de la primera vez a la reiterada aparición de la aurora, de lo esencial a lo pautado en el tiempo. Del paralelismo a la simetría, la inicial referencia a la pupila aparece en el penúltimo poema, y de nuevo con el mismo cambio que lleva de la plenitud del instante a la conciencia del tiempo, pues ahora ese otro yo al que se apela en segunda persona aparece «plegado en la pupila / que elige contemplar / desde el olvido» ${ }^{6}$. E cosi via.

El sentido casi metafísico del acceso a la temporalidad y su conciencia ${ }^{7}$ constituye el elemento de fondo de un ejercicio de evocación desdoblado en dos momentos o dos actitudes, atravesados por una sostenida relación del sujeto con una realidad aprehendida vital y sensorialmente, materializada en referencias muy concretas, por las que el lector queda situado ante

\footnotetext{
4 López Guil, Asia, op. cit., p. 15.

5 López Guil, Asia, op. cit., p. 27.

6 López Guil, Asia, op. cit., p. 37.

7 Para la sintonía con una estética de la trascendencia, véase Itzíar López Guil, «Hechuras del vacío'. Dos poemas de María Victoria Atencia», en El espacio del poema. Teoría y práctica del discurso poético, Itzíar López Guil y Jenaro Talens (eds.), Madrid, Biblioteca Nueva, 20II, pp. 313-327.
} 
el componente más inmediato del realismo. En ese universo textualizado se combinan los referentes individuales, cercanos en algún caso a lo más íntimo, a lo familiar (Asturias, una dirección en Roma, la edad de la protagonista...), con los propios de la historia, no con mayúsculas, pero sí colectiva, inseparablemente unida a la temporalidad; aunque este elemento aparece con menos individuación, como para evitar su limitación a la anécdota concreta, está latente en muchos versos, sobre todo cuando vibra el sentido de la separación obligada, de unos giros en la vida determinados por instancias ajenas, opresivas; y cuando estas se enuncian, camino del final, las consecuencias se muestran en toda su rotundidad, con precisión y efecto dignos del mejor barroco:

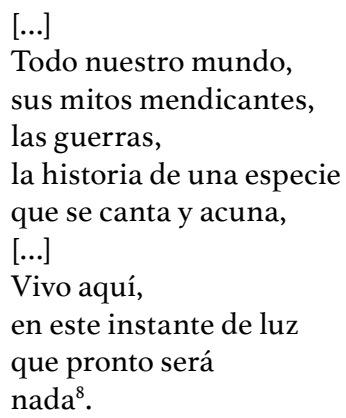

Como si se hubiera impuesto el olvido que, desde el final de «Olas», se contrapone a la memoria de las composiciones iniciales, se apunta la posibilidad del encuentro. Mientras en los últimos poemas se multiplica la dialéctica de la luz y de la sombra, del amanecer y de la noche, el camino parece borrarse, y multiplicarse las inclemencias y las amenazas, pero a ellas se llega con la afirmación de la voluntad, con la fuerza del encuentro, con el yo, con el otro. El avatar del personaje y la lectura de los versos nos dejan en un lugar de indeterminación, del que da cuenta cumplida el último poema de esta parte:

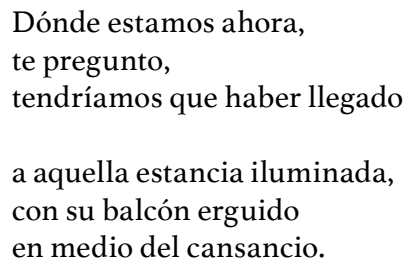

Dónde estamos ahora, te pregunto, tendríamos que haber llegado

a aquella estancia iluminada, con su balcón erguido en medio del cansancio.

8 López Guil, Asia, op. cit., p. 3 I. 




En el camino, el abrazo sostiene a un yo que ha encontrado a un tú; a su alrededor, quizá menos como una amenaza que como una razón causal, el mundo muestra su hostilidad y su fracaso; el sujeto no desconoce el tiempo ni la historia, y por ello se labra un espacio vital y emocional en el que guarecerse. No estamos ante un tiempo detenido y singular. El río de la vida y de la historia avanza, hasta dar en la mar. La mar es el morir, evocamos con Manrique. La mar es también el perpetuo movimiento, y en él las olas trazan su dinámica perpetua, de flujo y reflujo, en un devenir incesante que evoca el de los días que se marchan y el de la vida que se asienta.

El lector que vuelve la mirada hacia atrás (como hace el personaje que evoca su infancia, que es también un acto de lectura) puede reconocer un nuevo sentido en la dedicatoria, donde las aparición de los nombres de personas queridas en el entorno de la autora es mucho más que un puente entre la realidad y el texto, entre la vida de la casa y la escritura del gabinete. Al releer: «A Fernando, leal compañero de oleaje / A nuestra hija Ana / A mis padres, Pura y Carlos», las olas aparecen, más que en la referencia explícita, en el juego de las generaciones y en su aparente desorden temporal (igual-descendiente-ascendientes), que es, más bien, una profunda inmersión en un devenir de la temporalidad que no se somete a las leyes del calendario. Es desde el centro, del abrazo del presente, que emanan el futuro (como creación) y el pasado (como suelo firme). Promesa y memoria, como las olas.

También las olas protagonizan la cita que encabeza el volumen: «Waves breaking against the ship. / Against the beach. / And in the mind / of the horses, where / it is always Asia». Los versos reúnen las dos imágenes usadas para rotular las partes del libro, dejando en su posición final la que se eleva a título del poemario. Su diálogo ofrece una línea de lectura; su firma, Raymond Carver, una referencia estética. Entre todas ellas late una vibración,

9 López Guil, Asia, op. cit., p. 38. 
cristalizada más adelante en un rótulo de la parte final: vida y tono llano como materia y forma de la escritura ${ }^{\mathrm{IO}}$.

En el horizonte, tras el oleaje, Asia se perfila como el continente soñado, tan lleno de evocaciones de juveniles lecturas (Marco Polo, Gengis Khan, Kubla Khan, Miguel Strogoff...) como de un aura ideal, propicia a la huida y el refugio, a la recomposición de la identidad. Llanura interminable, Asia sirve también de puente entre Europa y América, en una imagen que trasciende la anécdota personal de la escritora, de la mujer real, y habla del encuentro y el reconocimiento en la otredad, para la que el exotismo del continente asiático proporciona el mejor telón de fondo, mejor, el escenario más cargado de sentido y de significación, aun cuando estos sean los del vacío. Pero es un vacío que puede llenarse, y la escritura es el medio para ello. Cuando hablamos de escritura levantamos acta de un ejercicio, de una conciencia y de un momento, tras los cuales se halla un sujeto, sostenido por ellos o, lo que quizá es lo mismo, sosteniéndolos. Hacia el oeste se apunta el declinar del sol, camino de las olas que lo consumen; hacia el oriente se apunta el amanecer, un nuevo amanecer, y al este se encuentra Asia, el final del viaje.

¿Y cómo es el continente textual que cierra el libro tras erigirse como su imagen definidora? Destaca, en primer lugar, el movimiento de reducción, pues pasamos de 23 a 5 piezas, en una sorprendente, paradójica inversión del tópico rasgo de la inmensidad de la geografía asiática. A cambio, se ve reforzada su simetría, mucho más perceptible para el lector, al tiempo que la brevedad le da más brillo a las llamativas llamadas de conexión intertextual de este apartado con el anterior. Así, en el primer poema de la segunda parte el verbo «desembocar» y el nombre de la galerna remiten al ámbito marino, como «pupila»y «luz» lo hacen a las imágenes con que se abre el libro; en el segundo poema es el árbol, igualmente presente en el poema 2 de la primera parte, el que establece las conexiones, asentando la imaginería del componente terrestre; el poema tercero y central nos devuelve al ámbito marino (surcar) y recupera también la imagen del encuentro corporal, con el beso; olas y árbol se encuentran en el poema cuarto, como referencias finales o conexiones con la parte previa, pues el poema quinto y final parece abrirse a un espacio nuevo, el que queda tras los actos simétricos de escribir y leer, como la vuelta a la vida al cerrar la página final.

La simetría es también el principio constructivo de esta breve serie: abierta con el poema «Dentro de mí», se cierra con «Dentro de ti», para formar un expreso marco, a un tiempo delimitación del espacio y señalamiento de una dirección. En medio se erige el lugar de encuentro, el espacio para el

Io Antes de Carver, hay que evocar en este punto a Wordsworth y a Auden, con su apuesta por el tono conversacional y el volumen sosegado para la poesía. 
reposo y la mirada: «La casa tiene cuatro ventanas» es el epígrafe destacado, y los versos ofrecen en la somera descripción de la arquitectura el mismo juego de simetrías en la disposición janual: «cuatro ventanas que se miran / y dos puertas de amor / en largo beso ${ }^{\mathrm{II}}$. En posiciones segunda y cuarta, alrededor del eje y entre los dos poemas-marco, otros dos poemas remiten a la dialéctica entre el tiempo (la vida) y su detenimiento, en un devenir en el que se anula el relieve, la altisonancia o hasta la expresividad de los momentos crepusculares, pues, si «La vida se escribe sin mayúsculas», el tiempo se identifica con «El cielo a mediodía»: susurro y cénit, términos no marcados, espacios de integración.

Sin embargo, simetría e integración no pueden confundirse con clausura, no dan en oclusión. El punto de fuga se marca doblemente por la tensión con la parte inicial, apoyada en las recurrencias semánticas, y, en sentido contrario, por la singularidad de los dos poemas finales, cuya particular disposición tipográfica los aleja del perfil consuetudinario, consagrado en los 26 poemas anteriores. No cabe hablar netamente de sendos caligramas, aunque el penúltimo evoca con su forma el perfil de un árbol, como el apelado en sus versos, y en el último podemos intuir una imagen circular asociada a la noción de interior aludida por el título, «Dentro de ti». El contrapunto estético no deja de apuntar una sensación de ruptura, de amarras que se sueltan respecto al discurrir previo del poemario y señalan hacia nuevos espacios, más abiertos, menos encomendados exclusivamente al plano de la razón, más necesitados de una complicidad en la recepción.

No son los únicos elementos de singularización apreciables en este quinteto de composiciones. En todos ellos se destacan unos rótulos, ya citados, compuestos por las palabras iniciales del poema, elevadas por su relieve tipográfico a la condición de títulos y, sobre todo, de balizas en una lectura en la que no se puede prescindir de los elementos de simetría y los juegos semánticos que establecen. En el otro extremo, el negativo, pero dentro del mismo código de relieve por medio de elementos no estrictamente textuales, se sitúa la omisión de los signos de puntuación y de otros elementos diacríticos (si no es el salto de verso o el juego con los espacios en blanco en la última composición) para pautar la lectura, como si la falta de fronteras no fuera exclusiva del evocado espacio de la geografía asiática, sino que se reclamara también para el poema, despojado de marcas de constreñimiento sintáctico y, por tanto, semántico. En este mismo plano de omisiones, pasaría quizá desapercibida la renuncia al uso de la mayúscula; ausentes los puntos y su separación de frases, desaparece también el correlato del inicio con letra capital, que solo sería llamativo en el arranque del poema. Sin embargo, la atención del lector queda retenida y vuelta a la relectura a partir

II López Guil, Asia, op. cit., p. 43. 
del encabezamiento del segundo poema y su rotunda declaración: la vida se escribe sin mayúsculas; como el poema, como los poemas. Porque quizá el poema no es otra cosa que la vida escrita, y sin necesidad de mayúsculas, de ese falso énfasis añadido, para avanzar en la comunicación.

Para ensayar una interpretación estética a partir de esta declaración, nos permitimos una lectura metapoética que no hay por qué imputar al texto, que funciona perfectamente en su nivel de un poema de amor:

\author{
la vida se escribe \\ sin mayúsculas \\ nos han dicho los árboles \\ mientras tú me besabas \\ no hay signos en la piel \\ de un largo beso \\ la vida se escribe \\ en el instante de \\ dos bocas \\ buscando su lugar \\ entre los árboles \\ sin mayúsculas ${ }^{12}$
}

La articulación del poema se apoya en dos elementos explícitos en la superficie textual: la escritura y el beso. Su recurrencia establece el ritmo semántico del texto, y su proyección los convierte en los ejes sobre los que gira en una dinámica de repliegue, casi centrípeta, y una línea de apertura, justo cuando otra repetición sortea la inercia hacia la clausura. La reiterada relación de los dos elementos, entre la metáfora y la metonimia, se ordena en los dos segmentos principales, dispuestos en torno a un centro. Así podemos considerar el breve dístico, aunque el verso suelto final solo permita establecer el eje de simetría, en sentido estricto, entre el espacio vacío de la segunda y la tercera estrofa. Otra opción aparece si apreciamos una correspondencia entre ese epifonema (con su eco del verso 2) y lo señalado en la segunda estrofa, ya que cuando las mayúsculas encuentran más imposibilidad de existencia es cuando no hay escritura, y esa parece ser la clave en la inflexión del discurso textual. La tensión semántica de esos dos versos (¿no hay sobre la piel signos de un largo beso, o no aparece ningún verso en la piel del beso?) apunta, en todo caso, a una contradicción de la correlación entre escritura y beso que parecía quedar establecida en la primera estro-

I2 López Guil, Asia, op. cit., p. 42. 
fa. Pese a lo moroso de su hacerse, el beso, el encuentro físico y espiritual, la unión total de los amantes, se opone a la escritura, al tiempo detenido que permitiría su imprimación. Su dilatado transcurrir se consuma en sí mismo, sin dejar signos, señales de sustitución, vanos intentos de paliar la ausencia o de superponerse a la presencia. El beso (a diferencia del verso) no imprime signos, no fija más trascendencia que su realización.

Alrededor de la sentencia el aparente paralelismo se mueve y altera, con el reflejo en la ampliación del número de versos tras el arranque anafórico. De la primera a la tercera estrofa el beso («tú me besabas») pierde su denominación, su límite, y se hace materia del tiempo y de los cuerpos ${ }^{13}$ («el instante / de dos bocas»). A la vez, los árboles dejan de enseñar una verdad («nos han dicho»), para acoger. Con un sutil desplazamiento el lector pasa de la cosificación convencional, susceptible de enterrarse en el diccionario, a la búsqueda de un lugar propio, a la construcción de un hogar entre los árboles, en un instante que puede hacerse perenne.

En la brevedad del poema, el eco convierte el primer verso en un Leitmotiv. Los juegos con el encabalgamiento (apoyados en el encadenamiento del título) introducen la ambigüedad bajo su forma de sentencia, y otro tanto podría decirse en la más sutil dualidad entre el valor impersonal y el reflexivo (¿Es escrita por alguien o se escribe a sí misma?), para conducir a una nueva indeterminación: la vida ¿se escribe durante un instante o en la superficie del mismo? En el primer caso, el beso se identifica con la vida, es la vida; en el segundo, la vida se hace relato en la espalda del tiempo, pero ya sabemos que los besos no dejan signos. Y es que la vida, si se escribe, lo hace en minúscula, por más que lo dilate el encabalgamiento inicial: el verso final lo reafirma y extiende el rasgo más allá de lo que delimita el arranque del poema. El beso, el poema, la vida no requieren del énfasis, ese afeite oscilante entre lo pretencioso y la opresión de un corsé, como la rigidez de la regla gramatical, como las normas del poema bien escrito. Sin ese signo de frontera (entre el silencio y el texto, entre la oración anterior y esta) el sujeto puede deambular libremente por Asia.

En clave estética, la opción de Itzíar López Guil por la minúscula materializa una opción en la pugna abierta acerca de las fronteras entre la prosa y la poesía, entre el lenguaje cotidiano y las formas de extrañamiento, entre la fluidez de lo que avanza hacia delante, casi en forma narrativa, y los recursos para la detención y espesamiento del texto, siempre vuelto sobre sí mismo. Como ocurre con los signos de puntuación, el rechazo a la mayúscula supone también un colocarse al margen de lo establecido, de la autoridad, de la Academia, y colocar la emoción en un lugar más profundo que en el

I3 En la cercanía de la práctica académica de López Guil, son significativos los planteamientos de Rita Catrina Imboden, Cuerpo y poesía. Procesos de presentificación del cuerpo en la lírica mexicana del siglo XX, Berna, Peter Lang, 2012. 
escaparate de la exclamación o del tono exaltado, mayúsculo. En el legado de la poesía de la experiencia y la otra sentimentalidad, con Asia se nos abre también una reflexión sobre sus límites y alcance, que nunca son los mismos cuando se sobrevuela el carácter epigonal. 